is too costly and the individual ceases the behavior. As the cost becomes disproportionately low for the reward, reinforcement properties fall off, but we assume more gradually than with an increase in cost. The reinforcement level might never go to zero on the $\mathrm{R}>\mathrm{C}$ side. An empirical study of two or three reward objects or events under a range of cost conditions would generate representative curves of the population of potential reinforcement levels around each reward under specific cost conditions.

If the relationship between reward-cost levels and behavior is more complex than a simple algebraic summation, as our results suggest, the basic propositions of exchange are not adequate to account for ongoing behavior. The concept of equivalence is proposed as a construct relating the relative, as well as the absolute, levels of reward and cost and their interaction.

\section{REFERENCES}

ADAMS, J. S. Inequity in social exchange. In L. Berkowitz (Ed.), Advances in experimental social psychology. Vol. 2. New York: Academic Press, 1965. Pp. 267-299.

ARONSON, E., \& LINDER, P. Gain and loss of esteem as determinants of interpersonal attractiveness. Journal of Experimental Social Psychology, 1965, 1, 156-172.
BARON, R. M. Social reinforcement effects as a function of social reinforcement history. Psychological Review, 1966, 73, 527-539.

BARON, R. M,, ROBINSON, E. L., \& LAWRENCE, $S$. The effectiveness of social reinforcement as a function of changes in rate of reinforcement. Journal of Experimental Social Psychology, 1968, 4, 123-142.

BLAU, P. M. Exchange and power in social life. New York: Wiley, 1964.

FESTINGER, L., \& ARONSON, E. The arousal and reduction of dissonance in social contexts. In D. Cartwright and A. Zander (Eds.), Group dynamics Evanston, Ill: Row, Paterson, 1960. Pp. 214-231.

GERGEN, K. The psychology of behavior exchange. Reading, Mass: Addison-Wesley, 1969.

HOMANS, G. G. Social behavior: Its elementary forms. New York: Harcourt, Brace, \& World, 1961.

LANZETTA, J. T. Information acquisition in decision making. In $O$. J. Harvey (Ed.), Motivation and social interaction. New York: The Ronald Press, 1963. Pp. 239-265.

LEWIS, M. Psychological effect of effort. Psychological Bulletin, 1965, 64, 183-190.

SIGALL, H., \& ARONSON, E. Opinion change and the gain-loss model of interpersonal attraction. Journal of Experimental Social Psychology, 1969, 3, 178-188.

THIBAUT, X. X., \& KELLEY, X. X. (1959)

THIBAUT, J. W., \& KELLEY, H. H. The social psychology of groups. New York: Wiley, 1959.

\title{
The effects of varying the number of conditioned leaders on group problem solving
}

\author{
STEPHEN L. COHEN and CABOT L. JAFFEE \\ University of Tennessee, Knoxville, Tenn. 37916
}

One hundred and twenty student Ss were divided into 30 four-man groups. The independent variable was the number of persons reinforced for verbal output in a group problem-solving situation. In 10 groups, only one person was reinforced; in 10 others two persons were reinforced; and in another 10 groups, all four persons were rewarded for their verbal participation. The dependent variables investigated were the amount of time necessary for solution of the problems and the total number of conflict remarks generated during those sessions. The results indicate that the 2TP groups took significantly longer to come to solution of the problem than either of the other two conditions. The number of conflict remarks, however, did not discriminate among treatments. The evidence suggests that the probable cause of the 2TP groups' poor performance is due to the significantly greater number of conflict statements generated by the initial high talker than were in the other two treatments.

Systematic observation of group behavior and the leader's place in the group have been widespread, but the variables altered have been, for the most part, group factors such as size, degree of homogeneity, task, etc. Little had been done with experimentally manipulating the overt verbal behavior of a person until Greenspoon (1955) reported his now-classic experiment in verbal conditioning, in which he was able to verbally reinforce $S s$ for particular speech categories. His experiment led to a good deal more research in the area of verbal conditioning and seems to have been the major impetus for an even more recent area of investigation concerning the conditioning of individuals within groups. Several authors have found that upon reinforcing the verbal output of a $S$ in a group, an overall increase results (Bavelas et al, 1965; Cohen et al, 1954; Dinoff et al,
1960; Jaffee \& Furr, 1968; McNair, 1957; Oakes, 1962; Oakes et al, 1960, 1961; Sidowski, 1954; Zdep \& Oakes, 1967), while at the same time punishing specific responses results in a decrease in their subsequent occurrence (Bachrach et al, 1961; Cieutat, 1959; Oakes et al, 1960).

It would seem then that the consistencies noted concerning the verbal conditioning of individuals apply equally as well for the small-group situation. The relationship between verbal conditioning and leadership was evident in studies by Aiken (1965), Bales (1950), Bass (1954), Bavelas et al (1965), Jaffee \& Lucas (1969), Riecken (1958), and Zdep \& Oakes (1967), in which group members rated those who spoke the most as the leaders of the group. Duration of speech in a group situation, then, has been shown to be an important aspect of leadership, at least, with regard to other group members' impressions.

One of the factors that has been ignored in the literature to date is the number of group members reinforced or punished within one group. Until now, in all of the experiments reported, only one member per group has been conditioned.

The question that is explored by the present study is: What is the effect of an increase in the number of leaders in a group-interaction situation?

METHOD

One hundred and twenty experimentally naive male students enrolled in the introductory psychology classes at the University of Tennessee were divided into 30 groups of four students per group. Three treatments were used: one with one reinforced S (1TP), one with two reinforced Ss (2TP), and one with all reinforced Ss (4TP), with 10 groups in each.

Each group was seated around a table in a room separated from a control room by a one-way mirror. A signal box (through which the $E$ was able to reinforce) was placed in front of each $\mathrm{S}$. The signal boxes contained two lights, one green and one red, visible only to the one particular individual seated before it. Only the green light was used for reinforcing group members for verbal participation. A microphone was placed on the table through which the Ss' discussions were monitored by the Es in the adjoining room. For a more detailed description of the experimental setting, see Jaffee \& Lucas (1969).

The experiment consisted of three different sessions given successively. The Ss were instructed that the $\mathrm{E}$ was interested in assessing group behavior and interaction when they were faced with discussion problems of varying complexity. The first 
session consisted of a 5 -min period in which each S's operant speech duration was recorded. The purpose of this period was to select those group members who spoke moderately in the group and who were then reinforced during the $15-\mathrm{min}$ second session. Prior to the start of the discussion, Ss were told that they would be signaled by the green light if, according to several trained and experienced judges, what they said during the discussion was considered of critical value in enhancing group discussion and a solution to the problem. Each target person was given exactly seven reinforcements per period, randomly distributed over the $15-\mathrm{min}$ period contingent upon the utterance of at least a complete sentence. The subject matter for this $20 \mathrm{mirl}$ was a short case-study problem, and the procedure was exactly the same for all groups.

After conditioning took place, the third and final session of $35 \mathrm{~min}$ consisted of the presentation to the groups of a leaderless group-discussion problem. Briefly, each $S$ assumed the position of a different city employee who, while concerned with maintaining an originally proposed budget for his own department, must cooperate with the other city officials in order to make an equitable group budget cutback.

In order to assess group performance, two dependent measures were investigated: time to solution, for each group, and number of total group conflict remarks as measured by Borgatta's revision of Bales's Interaction Process Analysis Categories (1963). These measures were both taken during the final 35 -min period.

\section{RESULTS}

Analyses of variance were computed to determine if there existed any significant differences between the three treatments (1TP, 2TP, 4TP).

Rank data were used for computation of solution time. The use of these data were preferred because of what can be called the "ceiling effect." A time limit, or ceiling, of $35 \mathrm{~min}$ was placed on the solution of the problem. The results of the analysis of variance for solution time demonstrated an $F$ significant at the .05 level of significance $(\mathrm{F}=4.28, \quad \mathrm{df}=2 / 27)$. A multiple comparisons analysis (Scheffé, cited in Hays, 1963, p. 484) indicated that the mean differences were significant only between the 2TP condition and each of the other two conditions. Far more interesting was the fact that $70 \%$ of the $2 \mathrm{TP}$ groups could not come to solution in the allotted time, whereas only $20 \%$ and $10 \%$, respectively, of the $1 \mathrm{TP}$ and 4TP groups were unable to solve the problem in the allotted time.

The analysis of variance computation for the average number of conflict remarks per treatment was insignificant $(\mathrm{F}=2.03$; $\mathrm{df}=2 / 27$ ). However, it was noted that the initial high talker who was later reinforced only in the 4TP groups generated a significantly greater number of conflict remarks in the 2TP groups than for either of the other treatments $(\mathrm{t}=2.05 ; \mathrm{t}=1.90$, $\mathrm{df}=9$ ).

\section{DISCUSSION}

The findings of this study indicate that one possible cause of group conflict might be due to the behavior of an initial high talker or leader in his interaction with other group members.

The interaction frameworks are very different for these three types of groups. In the 1TP, the initial high talker must compete with only one other member, the reinforced $S$, while in the 2 TP groups his competition comes from the other two reinforced members. However, in the 4TP groups the fact that the initial high talker is also reinforced apparently decreases his likelihood of eliciting conflict statements. The interaction between the high talker not being correct and the increased competition within a 2TP group is a potential area for further fruitful research.

The fact that the initial high talker maintained his operant speech level, without reinforcement, in $80 \%$ of the $1 \mathrm{TP}$ and 2TP groups, a finding further substantiated by Burroughs \& Jaffee (1969), provides the basis for competition in subsequent problem-solving situations. This point, coupled with descriptions of high talkers as outgoing and domineering personalities (Mann, 1959; Kaess et al, 1961; Shaw, 1959), further supports the probability of conflict emerging.

One final analysis is provided by Bass (1960), who sums up the cause of conflict in the group situation as the loss of esteem and status for the follower. That is, the follower becomes antagonistic and obstinate because of the lack of recognition he has received from the other group members. The fact that the high talker in the 2TP group has been unwillingly thrown into the role of a "follower" could very well explain the increased amount of conflict demonstrated in that situation.

\section{REFERENCES}

AIKEN, E. G. Changes in interpersonal descriptions accompanying the operant conditioning of verbal frequency in groups. Journal of Verbal Learning \& Verbal Behavior, $1965,4,243-247$.

BACHRACH, A. J., CANDLAND, D. K., \& GIBSON, J. T. Group reinforcement of individual response experiments in verbal behavior. In I. A. Berg and B. M. Bass (Eds.), Conformity and deviation. New York: Harper, 1961. Pp. 258-285.

BALES, R. F. Interaction process analysis: $A$ method for the study of small groups. Cambridge, Mass: Addison-Wesley Press, 1950. BASS, B. M. The leaderless group discussion.
Psychological Bulletin, 1954, 51, 470-495.

BASS, B. i. Leadership, psychology. and organizational behavior. New York: Harper, 1960. Pp. 301-340, 353-357.

BAVELAS, A., HASTORF, A. H., GROSS, A. E. \& KITE, W. R. Experiments on the alteration of group structure. Journal of Experimental Social Psychology, 1965, 1, 55.70.

BORGATTA, E. F. A new systematic interaction observation system: Behavior scores system (BSs). Journal of Psychological Studies, 1963, $14,25-44$.

BURROUGHS, W. A., \& JAFFEE, C. L. Verbal participation and leadership voting behavior in a leaderless group discussion. Psychological Record, 1969, 19, 605-610.

CIEUTAT, V. J. Surreptitious modification of verbal behavior during class discussion. Psychological Reports, 1959, 5, 648.

COHEN, B. D., KALISH, H. I., THURSTON, J. R., \& COHEN, E. Experimental manipulation of verbalization. Journal of Experimental Psychology, 1954, 47, 106-110.

DINOFF, M., HORNER, R. F., KURPIEWSKI, B. S., RICKARD, H. C., \& TIMMONS, E. O. Conditioning verbal behavior of psychiatric population in a group therapy-like situation. Journal of Clinical Psychology, 1960, 16-17, 371-372.

GREENSPOON, J. The reinforcing effect of two spoken sounds on the frequency of two responses. American Journal of Psychology, $1955,68,409-416$.

HAYS, W. L. Statistics for psychologists. New York: Holt, Rinehart, \& Winston, 1963.

JAFFEE, C. L., \& FURR, R. Number of reinforcements, conditioned leadership, and expectancy of reward. Journal of Social Psychology, 1968, 79, 49-53.

JAFFEE, C. L., \& LUCAS, R. L. Effects of rate of talking and correctness of decisions on leader choice in small groups. Journal of Social Psychology, 1969, 79, 247-254.

KAESS, W. A., WITNYOL, S. L., \& NOLAN, R. E. Reliability, sex differences, and validity in the leaderless group discussion technique. Journal of Applied Psychology, 1961, 45, 345-350.

MANN, R. D. The relation between personality characteristics and individual performance in small groups. Unpublished PhD thesis, University of Michigan, 1959. In L. Berkowitz (Ed.), Advances in experimental social psychology. Vol. 2. New York: Academic Press, 1965. P. 106.

McNAIR, D. M. The reinforcement of verbal behavior. Journal of Experimental Psychology, $1957,53,40-46$.

OAKES, W. F. Effectiveness of signal light reinforcers given various meanings of participation in group discussion. Psychological Reports, 1962, 11, 469-470.

OAKES, W. F., DROGE, A. E., \& AUGUST, B. Reinforcement effects on participation in group discussion. Psychological Reports, 1960, 7, 503-514.

RIECKEN, H. W. The effect of talkativeness on ability to influence group solution of problems. Sociometry, 1958, 21, 309.331.

SHAW, M. E. Acceptance of authority, group structure, and the effects of small groups. Journal of Personnel, 1959, 27, 196-210.

SIDOWSKI, J. B. Influence of awareness of reinforcement on verbal conditioning. Journal of Experimental Psychology, 1954, 48, 355-360.

ZDEP, S. M., \& OAKES, W. F. Reinforcement of leadership behavior in group discussion. Journal of Experimental Social Psychology, $1967,3,310-320$. 